\title{
Granulocytic sarcoma preceding AML M0 and the diagnostic value of CD34
}

\author{
E Astall, H Yarranton, J Arno, R Marcus
}

\begin{abstract}
Granulocytic sarcoma with no demonstrable abnormalities in the peripheral blood or bone marrow is a rare but recognised initial manifestation of acute myeloid leukaemia and has led to diagnostic difficulties in some cases. A lymph node excisional biopsy from a patient presenting with cervical lymphadenopathy, a mediastinal mass, and a normal peripheral blood picture was reported to have features suggesting a $T$ cell non-Hodgkin lymphoma, for which she was subsequently treated. However, 10 months later the patient developed acute myeloid leukaemia, FAB classification M0. The initial lymph node biopsy was reviewed and further immunohistochemical studies using antibodies against CD34 led to a revised diagnosis of primary granulocytic sarcoma.

(f Clin Pathol 1999;52:705-707)
\end{abstract}

Keywords: granulocytic sarcoma; CD34; lymphoma

Department of

Histopathology,

Addenbrooke's

Hospital, Hills Road,

Cambridge CB2 2QQ,

UK

E Astall

H Yarranton

J Arno

$\mathrm{R}$ Marcus

Correspondence to: Dr Astall.

Accepted for publication 21 April 1999

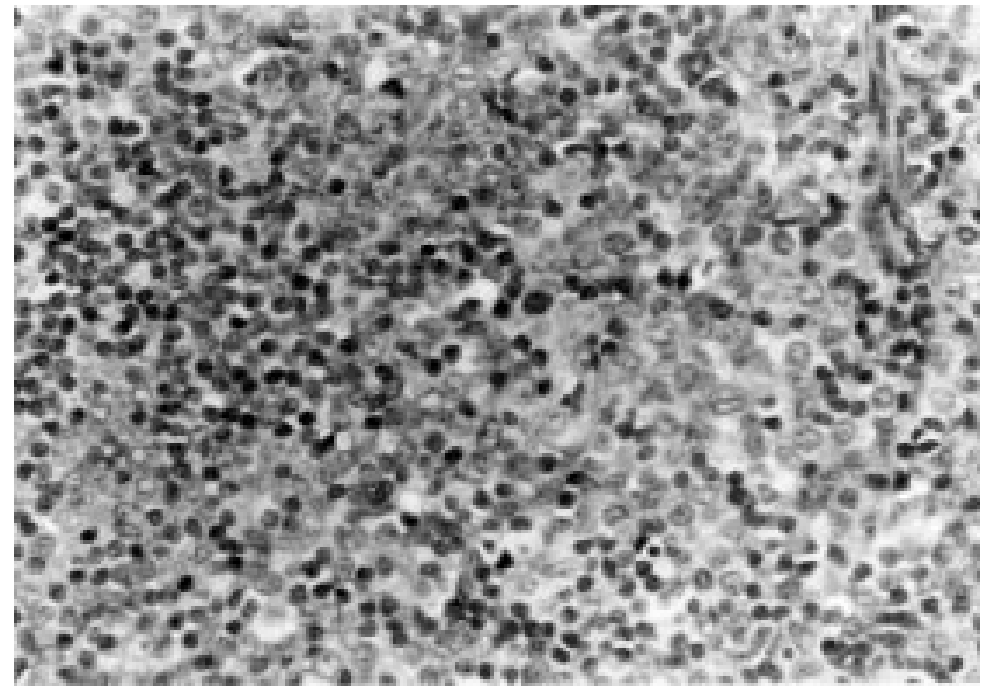

Figure 1 Lymph node showing infiltrating population of cells with oval nuclei, stippled chromatin, occasional small nucleoli, and scanty cytoplasm. Granulocytic sarcomas are extramedulla tumours composed of immature myeloid cells. They are usually associated with acute myeloid leukaemia (AML) and less commonly with blastic transformation of chronic myeloid leukaemia and myelodysplastic syndromes. In the majority of cases the diagnosis is made at presentation or during the course of AML but rarely the condition may occur as an isolated entity, which precedes the leukaemic phase by months or years. ${ }^{1}$ In such cases, granulocytic sarcomas may be misdiagnosed as lymphoma. ${ }^{2}$
This report illustrates the difficulties in such a case where the standard panel of special stains including chloroacetate esterase and lysozyme were negative; only subsequently was an antibody against early haematopoietic markers such as CD34 employed and found to be of diagnostic value.

\section{Case report}

In December 1996, a previously fit 42 year old woman presented to her local hospital with a one month history of a soft tissue swelling in her neck. Examination revealed a mass of lymph nodes in the left supraclavicular fossa ( 8 $\times 10 \mathrm{~cm})$ and a further mass $(3 \times 4 \mathrm{~cm})$ in the right anterior triangle of the neck. There was no palpable hepatosplenomegaly.

Laboratory investigations showed haemoglobin $14 \mathrm{~g} / \mathrm{dl}$, white blood cell count $6.5 \times$ $10 \%$ litre (normal differential), and platelets 402 $\times 10^{9} /$ litre. The biochemical profile was unremarkable. Computed tomography revealed additional superior mediastinal and right paratracheal lymphadenopathy.

A lymph node $(1.5 \times 1 \times 1 \mathrm{~cm})$ was excised

from the left cervical region. This tissue was processed for routine histopathological examination only. No fresh tissue was submitted for cytogenetic analysis. The features of the lymph node were effaced and a diffuse infiltrate of medium sized cells was present throughout; these extended beyond the capsule. The cells of the infiltrate had oval nuclei with stippled chromatin, occasional small nucleoli, and scanty cytoplasm (fig 1). Among them, cells undergoing apoptosis were conspicuous and occasional mitotic figures were present. The infiltrate was intimately mixed with small lymphocytes, which appeared unremarkable.

Initially, the impression was that the infiltrate consisted of lymphoid cells, and immunohistochemical staining showed them to be positive for CD45 and CD43, but antibodies for specific $\mathrm{T}$ cell and $\mathrm{B}$ cells antigens were negative. Although follicles as such were absent, immunostaining revealed that the infiltrate tended to spare B cell areas of the node. A possible diagnosis of acute myeloid leukaemia was entertained but CD15, chloroacetate esterase, and lysozyme staining all proved negative. No cytoplasmic granules could be recognised in a thin Giemsa section. In view of these findings the lymph node was referred for a further opinion. At the second laboratory, similar immunostaining results were obtained but the suggestion was made that it might represent an unusual type of peripheral $\mathrm{T}$ cell lymphoma since the infiltrate was CD43 positive. A bone marrow aspirate and trephine taken a month 


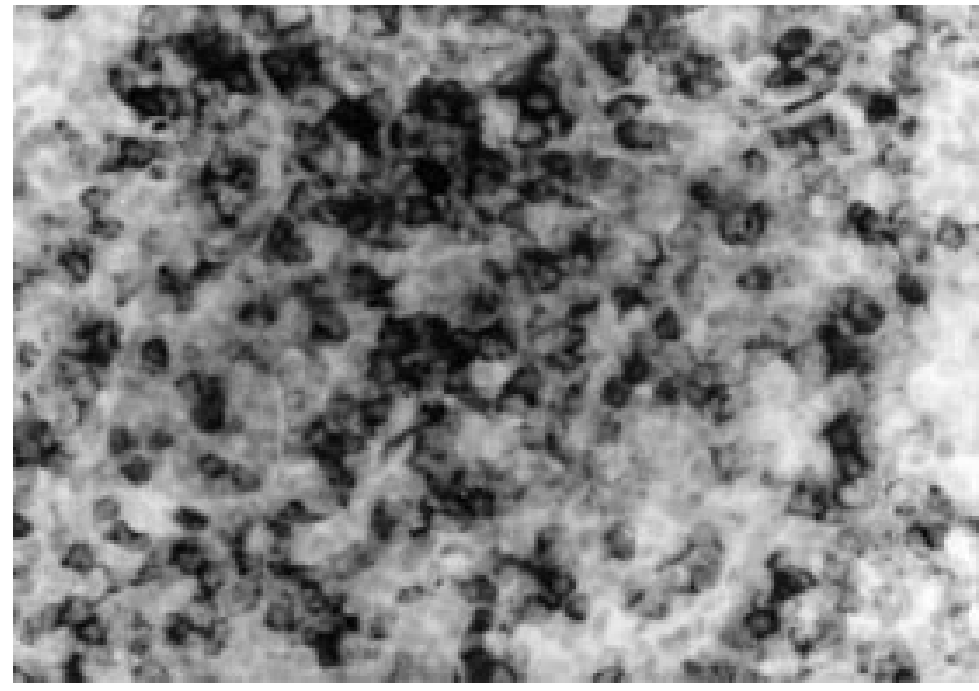

Figure 2 Lymph node showing strong positive reaction to CD34 (immunoperoxidase).

later showed normal cellularity with no lymphomatous involvement.

In the absence of any other diagnosis, the patient was treated with six three weekly cycles of CHOP chemotherapy (cyclophosphamide $750 \mathrm{mg} / \mathrm{m}^{2}$, vincristine $1.4 \mathrm{mg} / \mathrm{m}^{2}$, doxorubicin $50 \mathrm{mg} / \mathrm{m}^{2}$ all on day 1 , and oral prednisolone $100 \mathrm{mg}$ daily for five days). Repeat computed tomography showed partial remission and she subsequently received involved field radiotherapy, 35 Gy in 17 fractions.

Ten months after her initial presentation she was seen with a one month history of sore throat, dyspnoea, cough productive of white sputum, and occasional epistaxis. Examination revealed pallor, a systolic flow murmur, and mild hepatosplenomegaly but no lymphadenopathy.

Her haemoglobin had fallen to $5.9 \mathrm{~g} / \mathrm{dl}$, her white blood count was $123 \times 10^{9} /$ litre (blasts $112 \times 10^{2} /$ litre), and her platelet count $19 \times$ $10^{2} /$ litre.

A bone marrow aspiration now showed that the marrow was entirely replaced by small undifferentiated blasts with a high nucleus to cytoplasm ratio. Flow cytometry studies on the bone marrow aspirate showed the following cell markers: CD7 86\%, CD33 79\%, CD34 77\%, CD45 74\%, and CD13 68\%, while CD3, myeloperoxidase, and TdT were negative, findings consistent with AML of morphological FAB type M0. Cytogenetics performed on the bone marrow aspirate showed loss of chromosome 5 and trisomy 19 and 20-changes previously reported in myeloid disorders.

A bone marrow trephine performed simultaneously with the aspirate showed a packed marrow composed of a uniform population of moderately sized cells with oval nuclei, finely dispersed chromatin, and one or two small nucleoli. The cytoplasm was variable and granules were inconspicuous.

Following the diagnosis of AML, the initial lymph node biopsy was reviewed. Further immunostaining performed in view of the flow cytometry findings showed that the infiltrate in the node stained strongly positive for CD34 (fig 2), suggesting that the cells were of early haematopoietic origin. It was therefore concluded that this patient had initially presented with a minimally differentiated granulocytic sarcoma that had been misdiagnosed as a lymphoma, and had developed typical AML M0 10 months later.

Treatment was started with induction chemotherapy consisting of high dose cytarabine ( $3 \mathrm{~g} / \mathrm{m}^{2}$ twice daily on days 1,3 , and 5$)$. An anthracycline based regime was initially avoided in view of her previous anthracycline treatment. A bone marrow aspirate 18 days later showed refractory disease. After normal cardiac function was ascertained by echocardiography, her chemotherapy was changed to $\mathrm{ADE}$ (cytarabine $100 \mathrm{mg} / \mathrm{m}^{2}$, days 1-10; daunorubicin $50 \mathrm{mg} / \mathrm{m}^{2}$, days 1,3 , and 5; and etopside $100 \mathrm{mg} / \mathrm{m}^{2}$, days $1-5$ ). She achieved complete remission after this course of chemotherapy. This was followed by consolidation chemotherapy with a further course of ADE and then MACE (amascrine $100 \mathrm{mg} / \mathrm{m}^{2}$, cytarabine $200 \mathrm{mg} / \mathrm{m}^{2}$, and etopside 100 $\mathrm{mg} / \mathrm{m}^{2}$, days $1-5$ ).

Four weeks after her MACE chemotherapy she was readmitted in cardiac failure, and echocardiography showed features suggestive of a cardiomyopathy. She developed renal failure and died three days later. Necropsy findings were a dilated cardiomyopathy consistent with anthracycline toxicity; there was no evidence of a leukaemic relapse.

\section{Discussion}

Although rare, granulocytic sarcoma preceding acute myeloid leukaemia is a recognised phenomenon. ${ }^{4}$ Clinically and histologically, such a presentation may mimic an aggressive non-Hodgkin lymphoma. Granulocytic sarcomas, especially when minimally differentiated, may be difficult to distinguish from lymphoma. In particular, they often lack characteristic myeloid features such as demonstrable chloroacetate esterase activity. ${ }^{5}$ In such cases, routine immunohistochemical analysis may produce conflicting results, making a diagnosis difficult. The use of antibodies against CD34, which is expressed in acute myeloid leukaemias, ${ }^{6}$ may provide a useful addition to a panel of antibodies in these unusual cases, facilitating identification of cells of myeloid origin and excluding lymphoma.

CD34 is a molecule of unknown function expressed on haematopoietic stem cells, vascular endothelium, and dendritic cells. CD34 is not expressed in lymphomas or mature peripheral blood cells but is expressed on leukaemic cells of both myeloid (including granulocytic sarcoma) and lymphoid origin. ${ }^{7}$ In one study, approximately $30 \%$ of well and poorly differentiated granulocytic sarcomas were CD34 positive, but in cases of blast type granulocytic sarcoma, positivity rose to $60 \% .^{5}$

In our case of minimally differentiated granulocytic sarcoma, even though chloroacetate esterase and lysozyme were negative, perhaps the CD43 positivity should have suggested the possibility of myeloid leukaemia rather than a lymphoma, as other evidence did not support the latter. CD43 is known to be 
expressed on myeloid tumours and some monocytic tumours (as well as the majority of diffuse low grade B cell lymphomas).

Granulocytic sarcoma preceding AML is rare, with only 154 cases reported between 1965 and 1995. Nearly half of these were initially misdiagnosed as lymphoma. The FAB types of the subsequent AML in the majority of cases are either M1 or M2; however, M4, M5, and M7 have been described. ${ }^{8}$ In our case, the granulocytic sarcoma preceded AML of FAB type M0, which to our knowledge has not been reported previously.

Granulocytic sarcomas may resemble lymphoma morphologically, but the lack of expected immunohistochemical markers should alert the pathologist to the possibility of a granulocytic sarcoma. In such cases, the addition of CD34 to the standard panel of immunohistochemistry may help to elucidate the correct diagnosis.

1 Ersboll J, Petri J, Jenen KH, et al. Granulocytic sarcoma preceding acute myeloid leukaemia. Scand 7 Haematol preceding acute

2 Grange MJ, Cywiner-Golenzer C, Caen JP. Granulocytic sarcoma of the small intestine: a case report. Nouv Rev Fr Haematol 1988;30:251-3

3 Mansi JL, Selby PJ, Carter RL, et al. Granulocytic sarcoma: a diagnosis to be considered in unusual lymphoma syndromes. Postgrad Med f 1987;63:447-9.

4 Van Veen S, Kluin PM, De Keizer RJW, et al. Granulocytic sarcoma. Am f Clin Pathol 1991;95:567-71.

5 Traweek ST, Arber DA, Rappaport H, et al. Extramedullary myeloid cell tumours. An immunohistochemical and morphological study of 28 cases. Am f Surg Pathol 1993;17: phologica

6 Traweek ST. Immunophenotypic analysis of acute leukaemia. Histopathology 1992;99:504-12.

7 Van de Rijn M, Rouse RV. CD34: a review. Appl Immunohistochem 1994;2:71-80.

8 Byrd JC, Edenfield JW, Shields DJ, et al. Extramedullary clinical review. F Clin Oncology 1995;13:1800-16. 